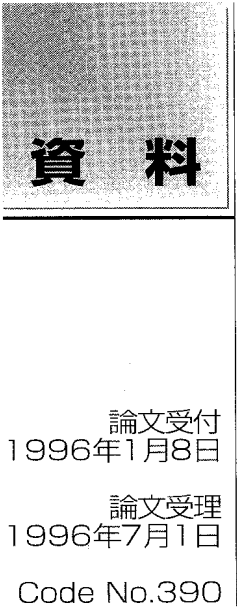

\section{1. 緒 言}

近年，施設内の情報伝達には，Local Area Network (LAN)などのネットワークが使用されはじめている. さらに，世界的規模のコンピュータネットワークであ るInternetを使用すれば，世界中から必要な情報が容 易に入手できる時代である ${ }^{1}$. 画像診断機器として使 用されているComputed Tomography $(\mathrm{CT})$, Magnetic Resonance Imaging(MRI), Digital Subtraction
Angiography (DSA), Single Photon Emission Computed Tomography (SPECT), Fuji Computed Radiography (FCR) などの医療機器から得られる画像情報はデジタ ルデータであるため，最近普及してきているネットワ ークを介して他の場所に容易に転送することが可能で ある。

上記医療機器から得られたデータを処理するUNIX ワークステーションは, 他のコンピュータとネットワ

\title{
Establishment of a Connection between Nuclear Medicine Imaging Equipment and a Personal Computer
}

\author{
SEIJI KAWAMURA ${ }^{1)} \cdot$ NORIYOSHI UMEZAKI $^{2)} \cdot \mathrm{KENICHIROU} \mathrm{KAJIWARA}^{3)}$ \\ DAISUKE AKAMINE ${ }^{1)}$. TOHRU MINOHARA ${ }^{1)}$. HIDEMICHI KAWATA ${ }^{4}$ \\ NORITADA NAKASHIMA4) • MASATOSHI ISHIBASHI5) SEIICHIROU MORITA5) and \\ NAOFUMI HAYABUCHI5)
}

1 ) Division of Nuclear Medicine, Kurume University Hospital (Center for Diagnostic Imaging)

2) Radioisotope Institute for Basic and Clinical Medicine, Kurume University School of Medicine

3) First Department of Surgery, Kurume University Faculty of Medicine

4) Center for Diagnostic Imaging, Kurume University Hospital

5) Department of Radiology, Kurume University School of Medicine

Received Jan.8,1996; Revision accepted Jul.1,1996; Code No.390

\section{Summary}

We constructed a network in our nuclear medical facility that connected a UNIX workstation(nuclear medicine data processor), DOS/V machine and Apple Macintosh computer. Data can be transferred using a FTP(Fetch 2.1) program and are displayed using NIH Image on the Macintosh computer. Fetch 2.1, a FTP program for Macintosh, performs well although it is inexpensive shareware. The NIH Image program was used to display image data on the Macintosh computer. This program is freeware distributed by the National Institutes of Health $(\mathrm{NIH})$. It supports a variety of image data formats, including ACR/NEMA2.0. Furthermore, the network was employed to shorten the time required for data conversion using FD. We can readily transfer image data to the presentation software without deterioration in image quality. In conclusion, we believe that this network decreases working time and increases data processing power. 
一ク構築を目的としたTransmission Control Protocol/ Internet Protocol(TCP/IP) プロトコルおよびEthernet端 子を標準で装備2)している。また，最近のパーソナル コンピュータ(以下，パソコン)はネットワークを構築 するための環境は非常に充実しており，物理的には容 易にUNIXワークステーションと接続できる。しか し，核医学検査室とパソコンを設置している読影室間 のわずか30mの距離の情報伝達さえもインターフェー ス，ソフトウェアなどを必要とするため容易に接続で きないのが現状である。

ネットワークの利点は，データ転送以外にも端末の コンピュータから他のコンピュータを遠隔操作 (telnet)することにより必要な情報の取得, 画像処理, 数 值処理ができ2)，業務の効率化と資源を有効に利用す ることが可能となることである。

今回, EthernetケーブルおよびInternetのanonymous FTP(脚注1) から得られる安価なfile転送ソフトウェア を用いてUNIXワークステーションとパソコンを接続 したネットワークを構築し, 画像fileの転送およびス ライド作製等に良好な結果を得たので報告する。

\section{2. 村料および方法}

\section{2-1 使用機器}

ガンマカメラ

:RC-2600I, RC-1500I

(日立メディコ製)

制御用パソコン：DOS/Vマシン

画像処理装置：ワークステーションRW-3000

(IBM製)

$\begin{array}{ll}\text { CPU } & : \text { RS6000 (64bit) } \\ \text { OS } & : \text { AIX3.2 } \\ \text { パソコン } & : \text { Quadra 840AV } \\ & \text { (アップルコンピュータ製) } \\ \text { OS } & : \text { System 7.1.6 } \\ \text { RAM } & : \text { 24MB } \\ \text { モニタ } & : \text { Flex Scan T560i-J (NANAO製) } \\ \text { フィルムレコーダ } & : \text { Color Fast } \\ & \text { (GCC TECHNOLOGIES製) }\end{array}$

Ethernet

2-2 使用ソフトウェア

Macintosh用クライアントソフトウエア

: NFS/Share

$$
\begin{aligned}
& \text { (クニリサーチインターナショ } \\
& \text { ナル製) }
\end{aligned}
$$

network controlソフト

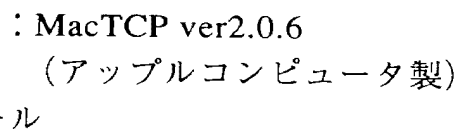

: Adobe Photoshop3.0J

(Adobe Systems Incorporated 製)

\section{2-3 方 法}

ガンマカメラRC-2600I とRC-1500Iで収集された核 医学データは，Fig.1に示すように制御用DOS/Vパソ コンを介してRW-3000に転送されるように構成されて いる.RW-3000では種々の画像処理が行われ診断に供 される，核医学検査室とQuadra 840AV (以下Quadra)

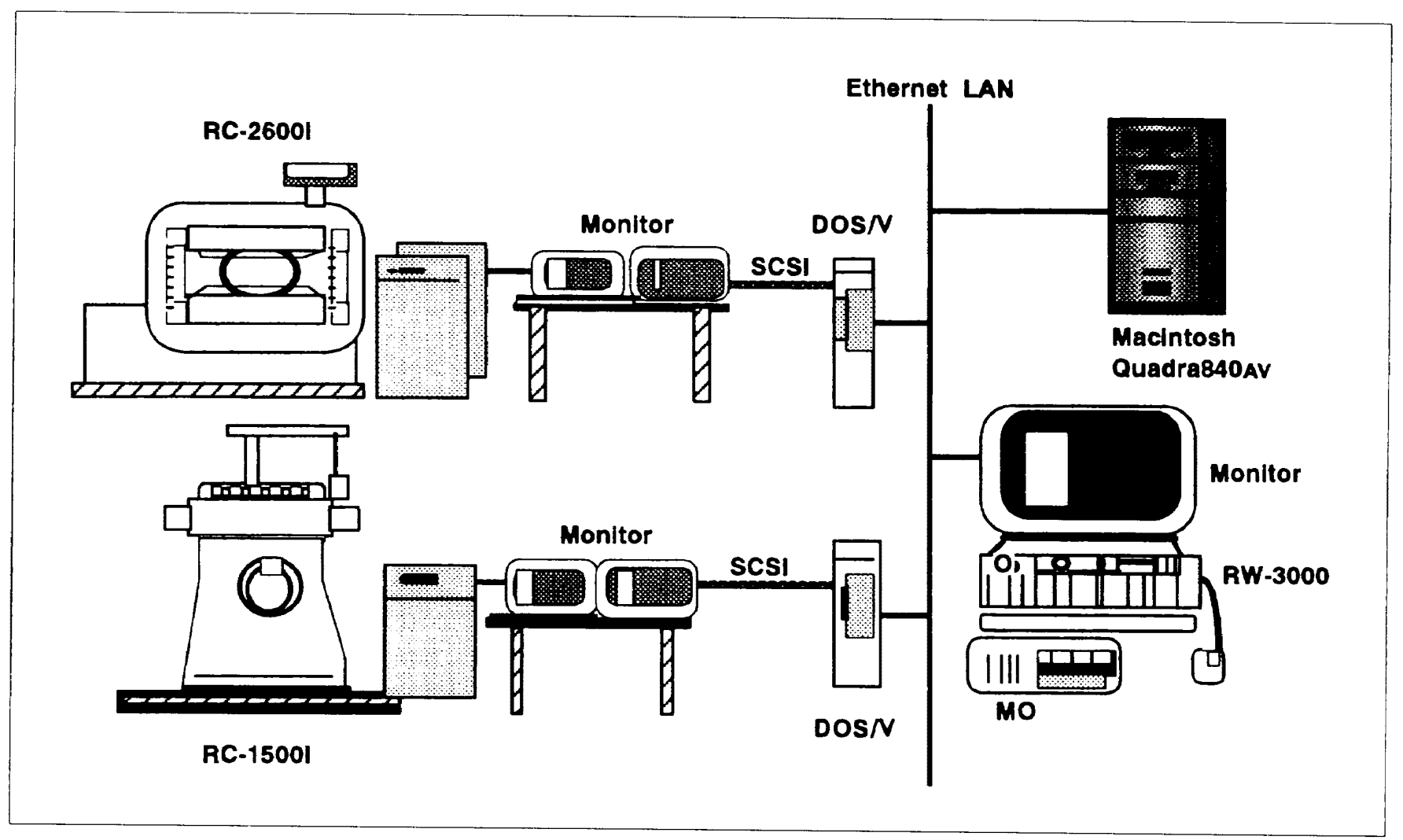

Fig. 1 Nuclear medicine imaging system consisting of gamma cameras, a UNIX workstation, and an Apple Macintosh computer. 
が設置さ秃ている読影室は䄪 $30 \mathrm{~m}$ の距離があり，Fig.1に示すよう に読影室のQuadraとRW-3000を Ethernet走全して接続した。今可 Internet経由で入手し使用したシ エアウェアとフリーソフトウェ アをTable 1に示子。Quadraと RW-3000の通信にTCP/IPを用い るため, QuadraにMacTCPをイン ストールした。RW-3000側の通 信環境設定は，このマシンの標隼ツールであるSystem Management Interface Tool(SMIT) 老用いて行った。 Network File System (NFS)!こよるfileの共有は, Quadra にNFSアプリケーションであるNFS/Shareをインスト ールしてTCP/IPプロトコルで通信する方式である。 NFSを使用子るために，SMITを用いてnfsデーモンを 起動させ，/etc/passwd および/etc/groupにQuadra利用 者のユーザ登録を行い, かつファイル共有として解放 するディスクのディレクトリを/etc/exportに記述し た。また，letc/hosts fileにQuadraのIPアドレスを設先 した。こ扎らの設定を行いNFS/Shareクライアントソ フトウェアの起動により, QuadraのセレクタからRW3000側のNFS+ーバを認識可能々なった。さらに， Fetchを用いたRW-3000からQuadraへのfile転送および NCSA telnet朋いたQuadraからRW-3000の遠隔操作 を可能とした。

ネットワークの初期設定IPアドレスはRW-3000 (192.0.0.254), Quadra(192.0.0.140), RC-2600IServer (192.0.0.248), RC-15001Server(192.0.0.253)となって おり，こ机らのたから番目の0を1に変更し， (192.0.1.254)の様に設宝した。

テスト通信は，RW-3000からUNIXのpingコマンド により，パケット信号をQuadraに送信Lerrorをカウン トした。また，QuadraからNFS/Share添付のNFS/ Test ${ }^{\text {TMt }}$ 用いて，RW-3000のhard disk (HD) 在NFS サ ーバとして認識すること在確認した，RW-30000日立 メディコ独自形式の画像file 老W-3000に内臟された File Conversionソフトウェア（日文メディコ製）を朋い TAmerican College of Radiology/National Electorical Manufacturers Association(ACR/NEMA)に準拠した画 像フォーマットにデータ変換を行い，Fetchおよび NFS/Shareを䏳てQuadraに転送した。さらに，転送 した画像fileを画像表示ソフトであるNIH Image拈よびPhotoshopを用いて表示した。この 際，データ軽送ソフトによる沺像file転送時 間および画像表示ソフトによる画像表示時 閒をそれぞ机計测した。また，フロッピー ディスク (FD) を湖たオフラインによる画 像file転送時間を計測した。

\section{3. 結 果}

pingコマンドによりネットワークにパケッ

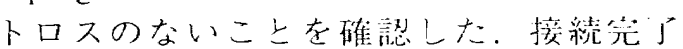

1996 年: 9 月
Table 1 Software obtained from the Internet

$\begin{array}{ll}\text { Virtual terminal software } & \text { : NCSAtelnet ver 2.6.2 (NCSASoftware Development) } \\ \text { File transter software } & : \text { Fetch } 2.1 \text { (Trustees of Dartmouth College) } \\ \text { Images processing software } & : \text { NIH Image V1.57/68k } \\ \text { (Anonymous FTP : ftp.kurume-it.ac.jp/.kenchan/ftp/pub/graphic-tools/mac/nih-image) } \\ \text { (Nifty Serve : Bio Forum Liblary : FBIO (LIB3)) } \\ \quad: \text { ACRNema (Plugin) } \\ \text { (Anonymous FTP : ftp.nig.ac.jp/pub/graphic/dicom/photoshop-acr-nema.hqx) }\end{array}$

後，QuadraはRW-3000のHDをあたかも自分のHDの ように諗識しかつ操作できた。 RW-3000の画像fileを Quadraで画像表示寸るためにACR-NEMA2.0フォーマ ットに変換した，変換後の画像fileはexport directoryに 格納さ机，こ扎以後の画像file転送は，Quadraから行 えるようにした，Quadra側でfile転送ソフトNFS/Share またはFetchを起動すると，Quadra側のdisplayにRW3000 上共有されたexport directoryが表示され容易に RW-3000側のfileを転送できた。 Fetchを用いてのRW3000からQuadraへの画像file転送抢よびNIH Imageを 用いた画像表示が可能であることを確認した。画像 file (2Mbyte) 転送時間と画像表示時間のソフトウェア の違いを，シエアウエア(脚注2)，フリーウェア(脚注 3)抢よび市販ソフトウェアで比較した結果をTable 2 お よびTable 3に示す. Fig. 2にRW-3000およびQuadraの displayに表示さ机た全身骨シンチグラフィーを比較し て示古。画像file転送時間をNFS/ShareおよびFetchで 比較すると，そ玌ぞ扎約15秒約13秒とシェアウェア であるFetchが転送は短時間で行われた。FDを用いた オフラインによる画像file (2Mbyte) 転送時間は数分を 要した。また，Quadraへ転送後，画像フォーマット TIFF形式で保存した全身骨シンチ画像(1Mbyte)の表 示時間は，Photoshop約3.3秒，NIH Image約1.4秒とな り，NIH Imageの方が高速に画像を表示した。

\section{4. 考 察}

画像フォーマットは世界的にDigital Imaging and Communications in Medicine (DICOM) フォーマットで 統一さ北ようとしている゙背景があり，そ狄はfile転送 のブロトコルの一つとしてTCP/IPを用いている。この ブロトコルは現在の広域ネットワークの世界では事実 けの標準さ上なっている。また最近Macintoshにおいて

Table 2 Data transmission time from RW-3000 computer to Quadra 840AV computer

Fetch 2.1 (Shareware)

$12.8 \mathrm{sec}(165 \mathrm{~kb} / \mathrm{sec})$

NFS/Share (Commercial software)

$15 \mathrm{sec}(140 \mathrm{~kb} / \mathrm{sec})$

Table 3 Comparison of display time of images according to software

Adobe Photoshop ${ }^{\mathrm{TM}}$ 3.0J (Commercial software) $3.3 \mathrm{sec}$ (1M:TIFF)

$\mathrm{NIH}$-Image (Free software)

$1.4 \mathrm{sec}(1 \mathrm{M}:$ TIFF $)$ 

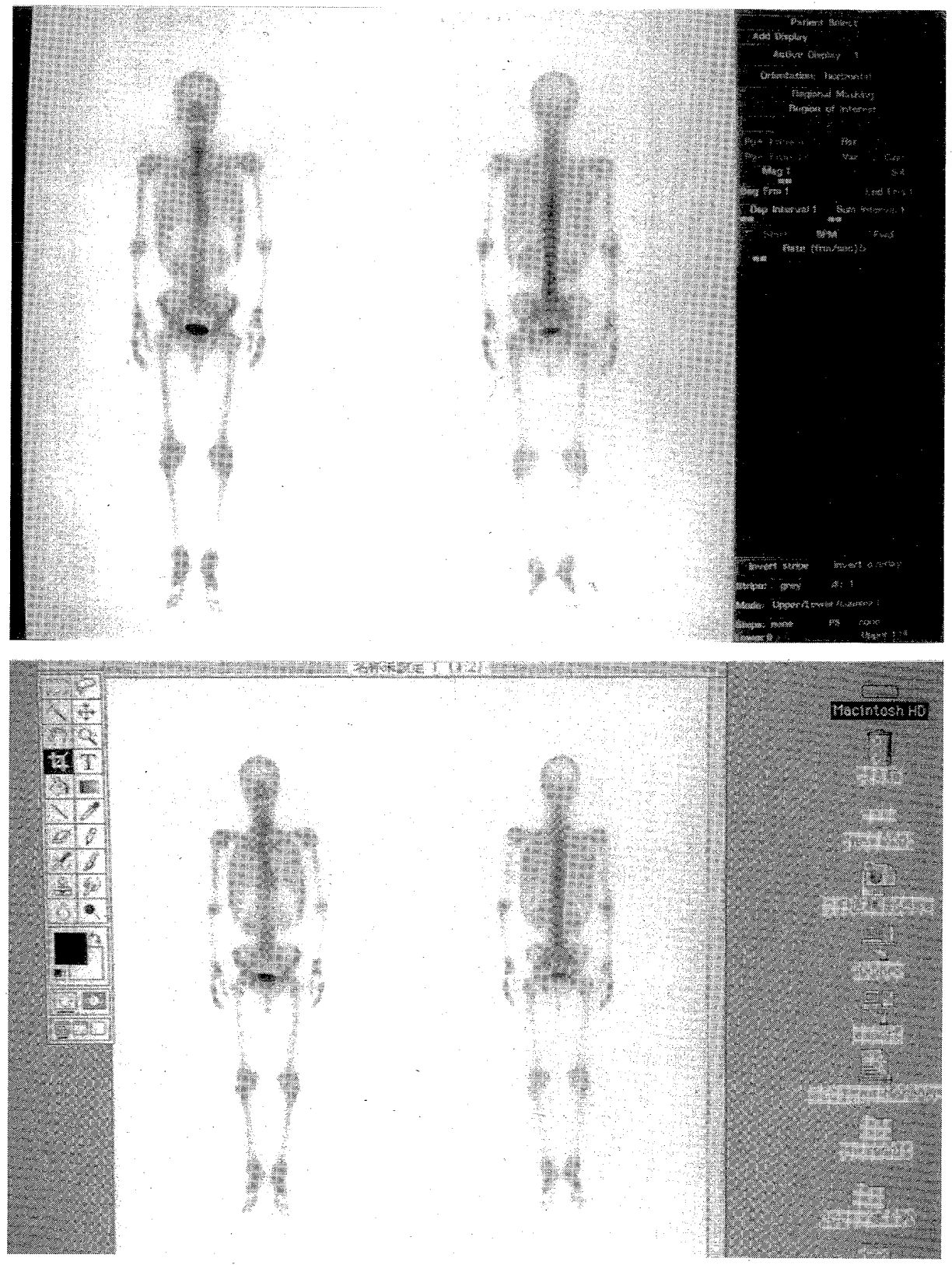

Fig.2 Whole-body bone image displayed by RW-3000 computer above and by Quadra computer below.

も TCP/IPは安定して稼働するようになってきている.

コンピュータ間の通信を行う時には, 下記の点を注 意する必要がある。

1) Ethernetの物理的接続は確実か.

2) 通信ソフトのインストールは正しく行われている 加。

3）通信ソフトの設定は正しく行われているか.

4)IPアドレスの確認

インターネットの通信プロトコルには，あらかじめ 用途の決められたIPアドレス (ComputerとComputerが 通信を行うときのIP層でのアドレスに相当)があり, 通信にはIPアドレスが重要な役割を持っている.IPア ドレスは 4 層で表示され, 各 8 ビット計 32 ビットで 示される5). 一般に(192.0.0.254)などの左から三番目 の0は，アドレスがわからないノード用に予約されて いるので使用することはできない. 我々のネットワー クを構成する各機器のIPアドレスはスタンドアローン
での使用を想定しての設定と考え られ前述した理由により使用でき ない. そこで, ネットワーク接続 された各機器の左から 3 番目のア ドレスを(192.0.1.254)の様に全て 変更した。このように1〜4を確 認後, RW-3000, Quadra双方か らアクセスすると, 両機種とも相 手の機種を認識しネットワークは 稼働した。

NFS/ShareおよびFetchのbinary モードによるfile (2Mbyte) 転送速 度は, それぞれ約 15 秒と約 13 秒 でありシェアウェアであるFetch の方が転送は短時間で行われた。

この転送速度はHDのアクセス速 度,インターフェイスの性能等に 影響を受けるので他の機種を使用 した場合は結果が異なると思われ る。一方，FDを用いたオフライ ンによる画像file (2Mbyte) 転送時 間は数分を要し，ネットワーク使 用時の 20 倍以上の時間を必要と した。2Mbyteの画像fileをFD (1.4Mbyte)を用いてオフラインで 転送するには, file圧縮, RW3000からFDへfile転送, FDから Quadra file転送, Quadraでのfile 解凍の手順が必要となる。このよ うにオフラインによるfile転送 は，ネットワーク使用時と比較し て数倍の手順が必要となる. 従っ て, 転送file数の増加に応じて転 送に必要な時間も増加する。

画像表示ソフトとして PhotoshopおよびNIH Imageにフ リーウェアのACRNemaをプラグインして用いた。 こ れらのソフトを利用するのは，ACRNemaをプラグイ ンすることで画像表示ソフトの機能が拡張し, ACR/ NEMA規格にフォーマットされた画像fileを展開表示 できるからである。このとき表示画像をPhotoshopあ るいはNIH Imageを用いてTIFF, PICT形式等で保存を 行えば，それらの画像展開時間はそれぞれ約3.3秒， 約1.4秒と高速で行うことが可能である。ここで, Photoshopの画像表示時間が遅いのは, 多機能でプロ グラムも大きく，自動的に仮想メモリーを設定して動 作することが原因となっていると考えられる。このよ うに, anonymous FTPには実際の仕事に利用でき役立 つフリーソフトが多数存在する. また, 今回のUNIX マシンの画像fileは 2 バイト $/ 1$ ピクセル画像であり, Quadra側でTIFF, PICTに保存された画像fileはQuadra の表示能力のため基本的に表示は8bitの濃度分解能と なる.しかし，Fig.2からもわかるようにマトリック 
スの大きい全身骨シンチ画像 $(1 \mathrm{k} \times 1 \mathrm{k})$ では視覚的にそ

の差を認めることは困難である。

核医学娭查により得られたデータは，最終的にフィ ルムまたは数值ハードコピーで診療サイドに提供され る。この中の貴重な画像をネットワークを利用して Quadraに取り込めばスライド作製などが短時間で可能 である.しかも， Power Point等のプレゼンテーション ソフトを使用し説得力のあるプレゼンテーションマテ リアルを作製可能である。同時に画像データはネット ワークを介してデジタルで転送されるため, 高品位の スライドをつくることができる，また，RW-3000で処 理された数值データを, Quadraに転送し表計算ソフト Excelなどを使用し統計処理6 も行える. 我々が使用し ているソフト，ハードを用いたシステムは，画像file 転送から画像表示までの時間が30秒以上必要，また Photoshopを用いたグレースケール階調の反転処理が 必要である等の問題があるが, 教育用のスライド作成 また画像処理の研究を行う上では問題ないと考える. 以上のように，ネットワークを用いれば種々の作業を より短時間で行うことが可能となる.

RW-3000の画像fileをACR/NEMA規格に変換する作 業をQuadra側で行うことができ机ば理想的であるが， QuadraのX Window環境が完全でないためX windowの GUI (Graphical User Interface)を用いての処理は難し い.コンピュータを操作する環境がMacintoshまたは WindowsのようにGUIであることは，Telnet等でコマ ンドを用いて操作するときには困難を伴うこともあ る。UNIXマシンと通信を行う時は，UNIXの基本コ マンドは熟知しておく必要があると考える。しかし， 不特定多数が操作する必要性が多くなった現時点では 全てGUIで操作可能な環境を整えることが急務であ り，そのため!MacintoshやWindowsマシン等のパソ コンを導入して使用することには，計りし机ないメリ
ットがある。しかし，現存する最大の問題点は画像フ オーマットが統一されておらず，機種毎に異なってい る点である。このような問題は, 現在電子保存のため の共通規格がDICOMデータフォーマットを含め検討 されており ${ }^{22}$ 行政と医療界および医療機器メ一カ一三 者がDICOMのような画像フォーマットを早期に採用 していくことで解決していくものと考える.

\section{5. 結 謤}

Internet経由で入手したソフトウェア利用によるネ ットワーク構築と利用法には，転送時間および画像表 示時間を今以上に高速化する必要がある等の問題点も ある。しかし, 我々の構築したシステムはUNIXマシ ン(RW-3000)からパソコン (Quadra)へのfile転送, お よび画像表示を安価に行うことができ，さらに業務の 效率化および資源の有效利用に役立つと考えられた。

この論文の要旨は「核医学圧縮画像が診断能に及ほ す影響の検討」として，第51回日本放射線技術学会総 会で発表した。

なお，今回利用したインターネット上の各種アプリ ケーションはftp://ftp.kurume-it.ac.jp/.kenchan/ftp/ graphic_tools/より入手した。このサイトにはJPEG系 の各種ツールやDICOM関連のツールが多数用意され ている.

脚注 1 ：パスワードなしでfile検索ができる機能10

脚注 2：個人で試験的に使ったり再配布することは自由だが, もし継続的に使用したり，会社などの組織で使用する 場合にはライセンス料もしくはそれに類する寄付を支 払うことを求めているい

脚注 3：ソフトウェアの著作者が，著作権を保持したま ま，通常は無償でソースまたはバイナリを公開し， その使用・改造・再配布を許可しているもの!

\section{参考文献}

1) Ed Krol著, 村井 純監訳：インターネットユーザーズガイ ド, p.113, インターナショナルトムソン・パブリッシン グジャパン, (1994).

2)稲垣高宏：はじめての人によくわかるUNIX, p.46-49,p.5051。西東社，(1993)。

3)梶原賢一郎：月刊新医療 7(DICOM上テレメディスンの可 能性)エム、イー振興協会, p.58-60. (1995).

4)竹下隆史, 荒井透, 获田幸雄：マスタリングTCP/IP入門 編, p.25-27，オーム社, (1994).

5)竹下隆史, 荒井 透, 芠田幸雄：マスタリングTCP/IP入門 編, p.196-197, 才ーム社, (1994).

6)パソコンからのUNIXデータベース利用法(クライアントー サーバ型システムの構築と梚証)，p.32，日経BP社， (1993).

7) 河村誠治，他：核医学圧縮画像が診断能に及ぼす響の娭
討. 日放技学誌, 51 (8), 1041, (1995).

8) Ken'ichiro Kajiwara: JPEG compression for PACS Computer Methodsand Programsin Biomedicine, 37, 343-351, (1992).

9) 梶原賢一郎：医用画像のデジタルファイリングの現状-特に 圧紑画像の臨床評価について。映像情報MEDICAL，23 (15) (434), 663-670, (1991).

10) Ed Krol著, 村井 純監訳：インターネットユーザーズガイ ド, p.62, インターナショナルトムソン・パブリッシング ジャパン, (1994).

11) UNIXシステム管理：スタンドアロン編, p.124-125, アス キー出版局，（1993）.

12) 奇稿 医用画像情報の電子保存のあらまし[第 1 版]「厚生 省健康政策局釉務課医療技術開発室」監修「財団法人 医 療情報システム開発センター」発行. 日放技学誌, 50(9), 1588-1601, (1994).

1996 年 9 月 